\title{
A study of balloon type, system constraint and artery constitutive model used in finite element simulation of stent deployment
}

\author{
A Schiavone ${ }^{*}$ and L G Zhao
}

\begin{abstract}
Background: Finite element is an effective tool to simulate stent expansion inside stenotic arteries, which provides an insightful understanding of the biomechanical behaviour of the whole stent-artery system during the procedure. The choice of balloon type, system constraint and artery constitutive model plays an important role in finite element simulation of stent deployment.
\end{abstract}

Methods: Commercial finite element package ABAQUS was used to model the expansion of Xience stent inside a diseased artery with $40 \%$ stenosis. The arterial wall, consisting of intima, media and adventitia layers, and the stenotic plaque were described by different hyperelastic models. Both folded and rubber balloons were considered and inflated with a linearly increasing pressure of 1.4 MPa. Simulations were also carried out by considering free, partially and fully constrained arteries.

Results: Folded balloon produces sustained stent expansion under a lower pressure when compared to rubber balloon, leading to increased stress level and enhanced final expansion for the system. Fully constrained artery reduces the stent expansion when compared to free and partially constrained arteries, due to the increased recoiling effect. Stress in the artery-plaque system has higher magnitude for stent expansion in a free artery due to more severe stretch. Calcified plaque limits stent expansion considerably when compared to hypocellular plaque. The negligence of the second stretch invariant in the strain energy potential leads to the disappearance of saturation behaviour during stent expansion. The use of anisotropic artery model reduces the system expansion at peak pressure when compared to the isotropic model, but with an increased final diameter due to reduced recoiling effect. The stress distribution in the artery-plaque system is also different for different combinations of artery and plaque constitutive models.

Conclusions: Folded balloon should be used in the simulation of stent deployment, with the artery partially constrained using spring elements with a proper stiffness constant. The blood vessel should be modelled as a three-layer structure using a hyperelastic potential that considers both the first and second stretch invariants as well as the anisotropy. The composition of the plaque also has to be considered due to its major effect on stent deployment.

Keywords: Stent deployment; Finite element; Folded balloon; Constraint; Constitutive model

\footnotetext{
* Correspondence: A.Schiavone@Lboro.ac.uk

Wolfson School of Mechanical and Manufacturing Engineering,

Loughborough University, LE11 3TU, Loughborough, UK
} 


\section{Background}

Coronary stents are essentially scaffolds, made of metallic alloys or biopolymers, used to sustain the blood vessels once expanded inside the obstructed arteries. Stents are generally deployed inside the diseased artery by means of an angioplasty balloon (except for self-expandable stents). The scaffold is placed over the balloon and expands with the balloon when this is inflated by internal pressure. This surgery procedure has minimal invasive nature and provides fast and effective solutions to patients suffering from coronary stenosis, a major cause of heart attack.

Finite element is an effective tool to simulate the process of stent expansion inside stenotic arteries, which helps to understand the insight of the biomechanical behaviour of the whole stent-artery system during the procedure. The simulations provide essential information regarding the behaviour of stent expansion, recoiling, dogboning and residual stresses, which can be further utilised to guide stent design and surgery procedures (Chua et al., 2003; Lally et al., 2005; Pericevic et al., 2009; Zhao et al., 2012a; Morlacchi et al., 2013). One factor that has important influence in the simulation of stent expansion is the type of balloon used in the modelling. Rubber balloons, inflated by internal pressure, were generally used to simulate expansion of early generation stents (e.g. PalmazSchatz). Modelling of a rubber balloon is relatively easy, and produces reliable results including both stent expansion and stresses in the stent-artery system (Chua et al., 2003; Ju et al., 2008; Schiavone et al., 2014). While De Beule et al. (2008) assessed the importance of balloon folding in the expansion behaviour of a Cypher stent and proved that the folded balloon was the only model that produced results consistent with the data provided by the manufacturer, in terms of diameter change as a function of pressure. This is particularly the case for the recent generation of stents (e.g. Cypher, Cordis) which are designed to be expanded by folded balloons. A study by Gervaso et al. (2008) compared three different methods in modelling stent expansion, i.e., no balloon (pressure applied on the stent inner surface), free rubber cylinder inside the stent and folded balloon. The work showed that the folded balloon gave the expansion behaviour of Cordis BX-Velocity stent closer to the company data. Martin and Boyle (2013) also showed that considering the tri-folded shape of the balloon led to an expansion curve of Cordis BX-Velocity stent closer to the manufacturer data. Although the importance of balloon type has been recognised in recent studies, a full comparison of stent deployment using a rubber and a folded balloon has not been carried out yet, especially the essential expansion behaviour and the stress distributions for the whole stent-artery system.

In stent deployment simulation, different boundary conditions have been proposed to constrain the rigid body motion of artery. For instance, Gijsen et al. (2008) performed a simulation of stent deployment in a realistic coronary artery, which was obtained by three-dimensional reconstruction of a mildly stenosed coronary artery. In this simulation, the artery was fully constrained at the ends to avoid translations and rotations. Results showed the arterial walls were successfully enlarged by the stent, with peak stress values observed on the thinner portions of the artery wall. Zahedmanesh et al. (2010) simulated the stent expansion in a realistic artery using foldedballoon geometry. The artery was constrained at its ends using connector elements with a stiffness of $1 \mathrm{kN} / \mathrm{m}$. Expansion of stent inside the artery was simulated by either inflating the balloon or applying internal pressure directly on the stent. Application of direct pressure to the inner stent surface was found to be incapable of accurately predicting stress-strain field and the deformed configuration of both the stent and artery. However, application of pressure with restraining elements, which prevent expansion of the stent beyond the desired diameter, may be used as a computationally efficient method to accurately predict the stress-strain field in the vessel wall following full stent expansion and recoil. Currently, there is a lack of investigation of the effects of different artery constraints on stent deployment simulations. Most of existing work tended to fix both ends of the artery in order to remove the rigid body motion completely, which might impose an over constraint to the system and affect the simulation results. The use of connector elements seems to be a plausible method to overcome the issue of over constraint, but still needs to be assessed against other types of constraints (e.g. full constraint and free of constraint) generally used in modelling of stent deployment.

The artery constitutive model is another important factor that needs to be carefully thought about for simulation of stent deployment. Holzapfel and Ogden (2010) reviewed the mathematical modelling of the mechanical behaviour of the human artery wall. This review showed the state of the art of development of constitutive models in the last ten years to describe the mechanical behaviour of artery tissue. It highlighted the highly nonlinear and anisotropic behaviour of the blood vessel tissue. This work also suggested that in many cases the artery behaves purely elastically and can be characterized by hyperelastic strain energy functions, including the layer specific constitutive models used to describe mechanical behaviour of arteries. For instance, Dixon et al. (2003) developed a constitutive model to describe the layer-specific properties of porcine coronary arteries. This model consisted of a two-parameter logarithmic strain energy function, with parameter values determined from comprehensive experimental data. Results showed that the model was able to fit the experimental data, showing consistency in the model parameters 
obtained for different branches of coronary arteries. Holzapfel et al. (2005) published an extensive experimental work to determine the layer-specific mechanical properties of the human coronary arteries. Their results showed that the intima is the stiffest layer over the whole deformation domain whereas the media in the longitudinal direction is the softest. They also proposed a strain energy function to model human coronary arteries as a composite structure composed of three solid mechanically relevant layers with different mechanical properties. Although strain energy potentials have been dominantly employed to describe the constitutive behaviour of blood vessels, the influence of different hyperelastic potentials in simulation of stent expansion has not been studied yet. In addition, state of the art of arterial constitutive modelling suggests the use of hyperelastic anisotropic models (Holzapfel et al., 2004; Holzapfel et al., 2005; Zhang et al., 2007), which are expected to affect the expansion behaviour of stent-artery systems in computer simulations (Nolan et al., 2014). However, we hardly come across published papers which used anistropic hyperelastic models to simulate stent deployment in diseased arteries, and existing computational studies are dominantly limited to isotropic models.

In this paper, computational analyses have been carried out to evaluate the effect of different modelling practices used in the simulation of stent expansion inside a diseased artery. In particular, the simulations using folded balloon and polyurethane rubber balloon were compared against each other in terms of diameter change, recoiling, dogboning and stresses for the whole stent-artery system. The effects of boundary conditions were assessed by comparing the stent expansion in fully constrained, partially constrained and unconstrained arteries. Simulation of stent expansion was also studied by considering different strain energy potentials used to describe the constitutive behaviour of blood vessel and stenosis. This work is of help and guidance for reliable finite element analyses of stent deployment in-vivo.

\section{Methods}

\section{Finite element model}

The finite element model for the balloon-stent-artery system is shown in Figure 1. The stent used for this analysis resembles the geometry of Xience stent, one of the latest commercial stents. The stent has a crimped diameter of $1.5 \mathrm{~mm}$, a length of $10 \mathrm{~mm}$ and a strut thickness of $80 \mu \mathrm{m}$. Using Abaqus CAE (ABAQUS, 2014), the complex geometrical pattern was first created on a flat sheet and then wrapped, along its central longitudinal axis, into the final cylindrical shape. The stenotic artery is modelled as a cylindrical tube and the stenotic plaque is assumed to be axisymmetric. The artery has a total length of $20 \mathrm{~mm}$, an inner diameter of $4 \mathrm{~mm}$ (healthy region) and a wall thickness of $1 \mathrm{~mm}$. The artery wall is considered to have three layers, namely intima $(0.27 \mathrm{~mm})$, media $(0.35 \mathrm{~mm})$ and adventitia $(0.38 \mathrm{~mm})$. The stenotic plaque has a length of $10 \mathrm{~mm}$, and its thickness gradually increases from zero at the distal section to $1.5 \mathrm{~mm}$ at the middle section (i.e., $40 \%$ restenosis at the middle section).

Two types of balloon are considered in this study. One is a cylindrical rubber balloon with a thickness of $0.5 \mathrm{~mm}$ and a diameter of $1.4 \mathrm{~mm}$, and the other is a folded balloon modelled as a shell surface. Both balloons have a length of $12 \mathrm{~mm}$. The folded balloons were created by extruding the cross section, with 3 folds, along the axial direction. Figure 2 shows the cross-sectional view of the rubber balloon and the folded balloon.

The artery, plaque and rubber balloon were meshed into hexahedral elements with reduced integration, which are mostly used to increase the computing efficiency and numerical convergence associated with large deformation, especially for soft tissues (Mortier et al., 2009; Zahedmanesh et al., 2010; Gastaldi et al., 2010; Zhao et al., 2012b). Nevertheless, a comparison between full and reduced integration elements has been made by looking at the von Mises stress averaged along the middle ring of the plaque surface, which confirmed the consistency of the results obtained using the two types of elements. The stent was meshed into incompatible

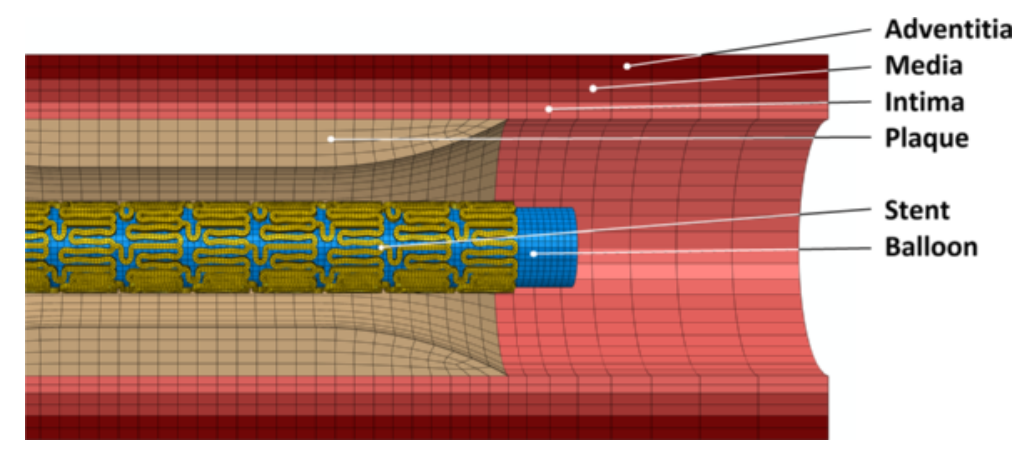

Figure 1 Finite element mesh for the Xience stent, the balloon and the stenotic artery. 

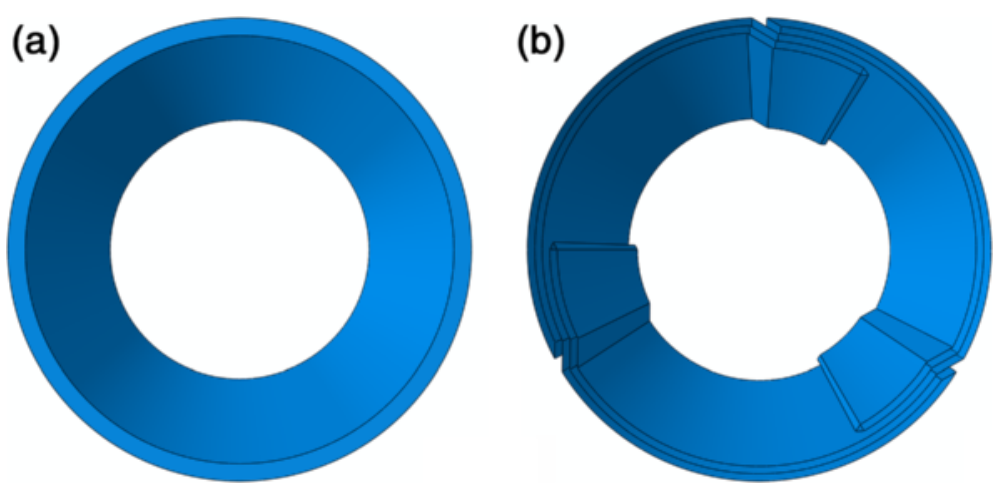

Figure 2 Cross section of (a) the polyurethane balloon and (b) the 3-folded balloon.

hexahedral elements (with full integration) in order to accommodate large bending deformation of the stent strut during expansion (Bower, 2008). This is also strongly recommended by Abaqus for stent deformation simulation (Simulia, 2010). The folded balloon was meshed using 4-node shell elements with reduced integration based on the consideration of computational efficiency. The number of elements is about 20,000 for the artery, with four layers of elements through the radial thickness, and about 50,000 for the stent, with four layers of elements through the strut thickness and two layers of elements across the strut width. The balloons were meshed into 4000 elements for the rubber one and $\sim 20,000$ elements for the folded one.

Contacts between the stent, the artery and the balloon were defined as hard contact with a friction coefficient of 0.25 (Ju et al., 2008). Varied boundary conditions were applied to the ends of the artery to study the effect of constraints on stent expansion. The rubber balloon was fully constrained at the two ends to simulate the fixed connection of the balloon to catheter. The folded balloon was constrained only in the axial direction while allowing the ends to expand freely in the radial direction.

All analyses were carried out using Abaqus explicit solver. The simulations consisted of two steps: the inflation step $(0.1 \mathrm{~s})$ in which the applied pressure increased linearly to the peak value and the deflation step $(0.1 \mathrm{~s})$ in which the pressure dropped linearly to zero to allow the recoil of the artery and the stent. The pressure was applied on the inner surface of the balloon. A peak pressure of 1.4 $\mathrm{MPa}$ was used in this study to ensure that maximum expansion was achieved in all cases. The incremental time automatically chosen by Abaqus is on the order of 1.0E$8 \mathrm{~s}$. The semi-automatic mass scaling (using a factor of 5) was used for both inflation and deflation steps, in order to reduce the computing time of the analysis. During the full process of analysis, the internal and kinetic energies have been monitored during the analyses, and the kinetic energy for whole the system was always less than $5 \%$ of the internal energy, which confirmed the validity of our quasistatic analyses (Gastaldi et al., 2010). Mesh sensitivity study has also been carried out, and confirmed the convergence of the results, in terms of stent diameter change, recoiling effect and residual stresses, for the mesh used in the present paper.

\section{Material constitutive behaviour Models for stent and balloon}

The Xience stent is made of Co-Cr L605 which is modelled as an elastic-plastic material with multilinear hardening segments based on the tensile stress-strain curve of the alloy in Figure 3a (Medtronic Technical Bulletin, 2003). The cylindrical rubber balloon is made of polyurethane which is described by a hyperelastic Mooney-Rivlin strain energy function:

$$
\mathrm{W}=\mathrm{C}_{10}\left(\mathrm{I}_{1}-3\right)+\mathrm{C}_{01}\left(\mathrm{I}_{2}-3\right)+\frac{1}{\mathrm{D}_{1}}(\mathrm{~J}-3),
$$

where $I_{1}$ and $I_{2}$ are the first and second stretch invariants, $J$ is the volumetric stretch (or third stretch invariant), $\mathrm{C}_{10}(\mathrm{MPa}), \mathrm{C}_{01}(\mathrm{MPa})$ and $\mathrm{D}_{1}$ are model parameters with values given in Table 1 (Chua et al., 2003). The folded balloon was modelled as a linear elastic material with Young's modulus of $900 \mathrm{MPa}$ and Poisson ratio of 0.3 (Gervaso et al., 2008). The stressstrain response of the two balloons is compared in Figure $3 \mathrm{~b}$, showing the folded balloon has a high stress levels for a given strain level due to its linear elastic behaviour and high modulus.

\section{The Ogden model}

As described in Section Finite element model, the artery consists of intima, media and adventitia layers which are all described by the third-order Ogden hyperelastic model (Zahedmanesh and Lally, 2009). The third-order Ogden hyperelastic strain energy potential is given by the following equation: 

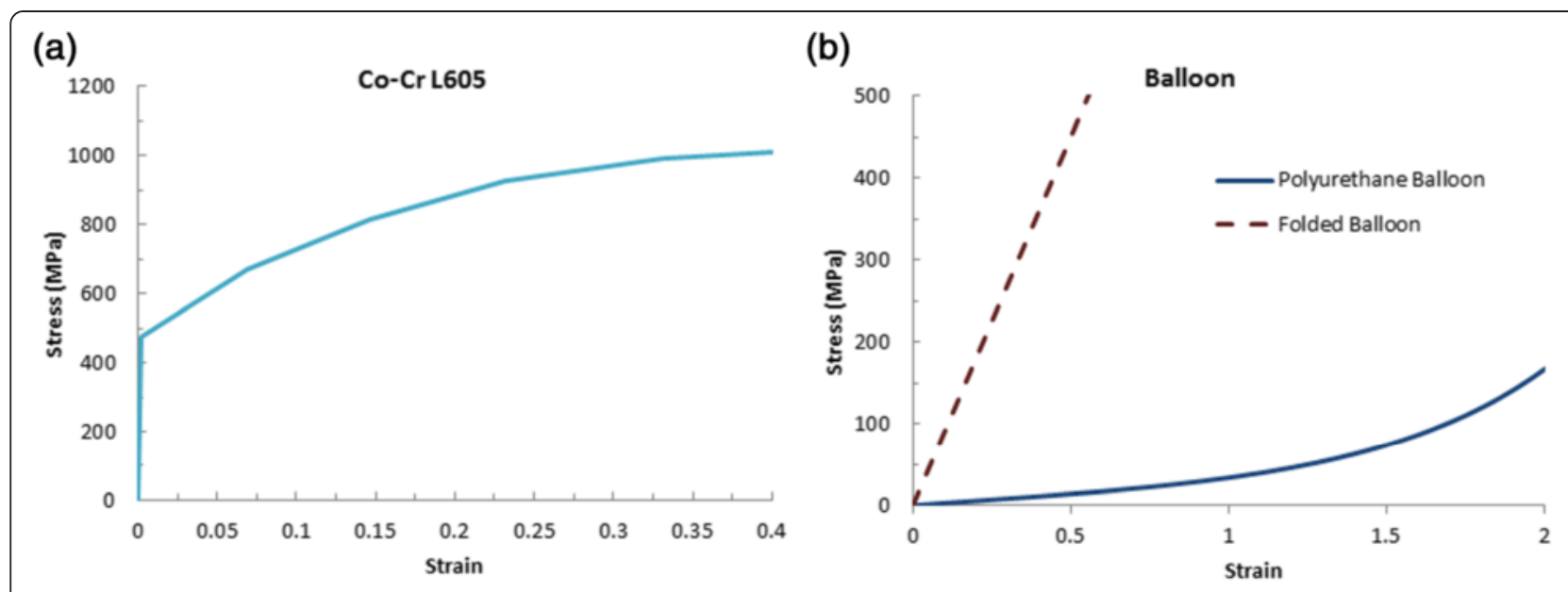

(c)

Ogden Model

(d)

Ogden Model
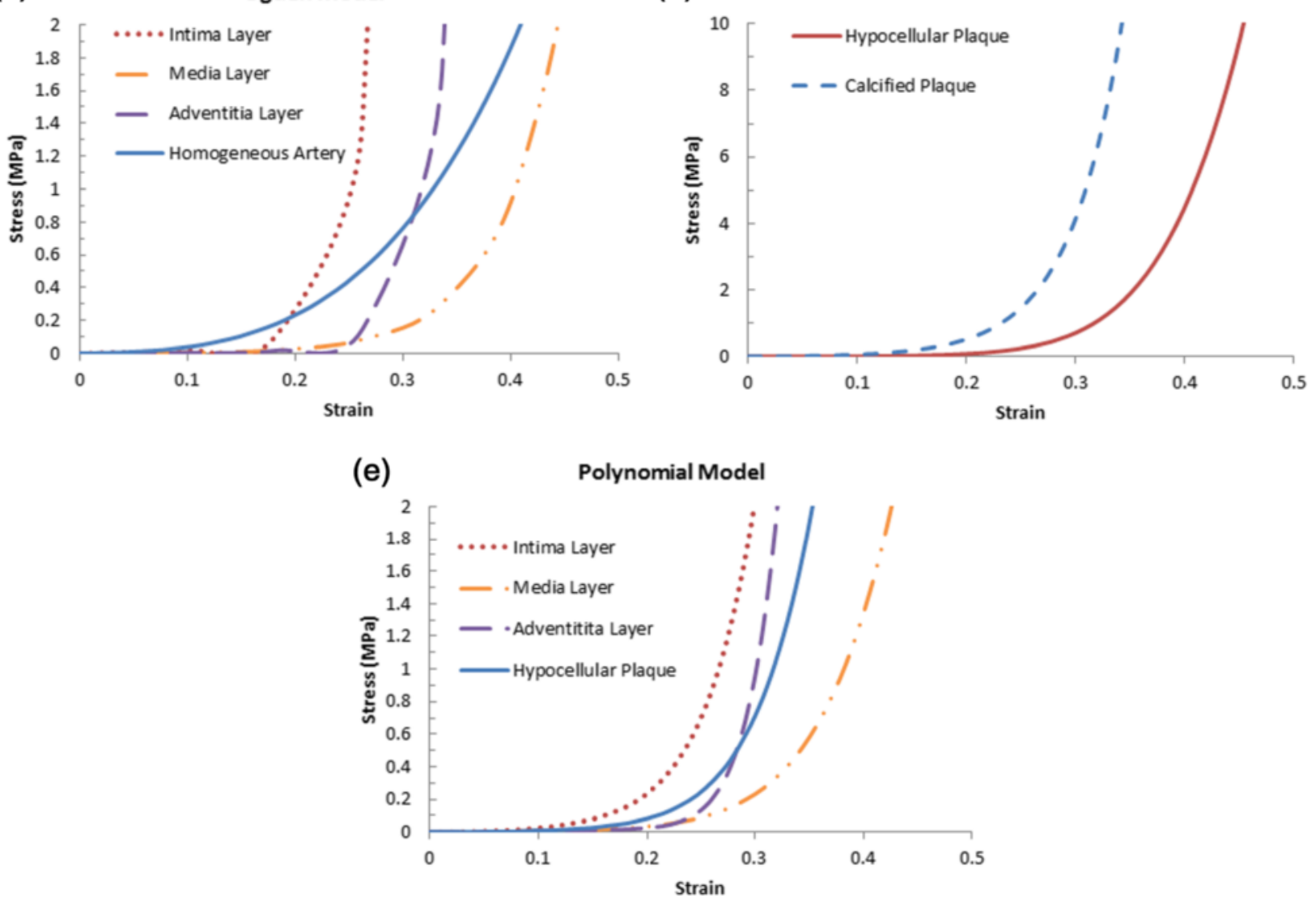

Figure 3 Stress-strain curve for (a) Co-Cr L605 alloy; (b) polyurethane balloon (Mooney-Rivlin model) and folded balloon (linear elastic); (c) three vessel layers (intima, media, adventitia) and homogeneous artery predicted from the Ogden model; (d) hypocellular plaque and calcified plaque predicted from the Ogden model; (e) three vessel layers (intima, media, adventitia) and the hypocellular plaque predicted from the polynomial model.

Table 1 Values of the Mooney-Rivlin model parameters for the polyurethane rubber balloon

\begin{tabular}{lllll}
\hline Material & $\boldsymbol{\rho}\left(\mathbf{k g} / \mathbf{m m}^{\mathbf{3}}\right)$ & $\mathbf{C}_{\mathbf{1 0}}$ & $\mathbf{C}_{\mathbf{0 1}}$ & $\mathbf{D}_{\mathbf{1}}$ \\
\hline Polyurethane & $1.07 \mathrm{E}-6$ & 1.03 & 3.69 & 0 \\
\hline
\end{tabular}

$$
W=\sum_{i=1}^{3} \frac{2 \mu_{i}}{\alpha_{i}^{2}}\left(\lambda_{1}^{\alpha_{i}}+\lambda_{2}^{\alpha_{i}}+\lambda_{3}^{\alpha_{i}}-3\right)+\sum_{i=1}^{3} \frac{1}{D_{i}}(J-1)^{2 i}
$$

where $\lambda_{i}(i=1,2,3)$ are the stretches in the three principal directions, and $\mu_{i}(\mathrm{MPa}), \alpha_{i}$ and $D_{i}$ are model 
Table 2 Values of the Ogden model parameters for the three vessel wall layers and the homogeneous artery

\begin{tabular}{lllllllll}
\hline Material & $\boldsymbol{\rho}\left(\mathbf{k g} / \mathbf{m m}^{\mathbf{3}}\right)$ & $\boldsymbol{\mu}_{\mathbf{1}}$ & $\boldsymbol{\mu}_{\mathbf{2}}$ & $\boldsymbol{\mu}_{\mathbf{3}}$ & $\boldsymbol{a}_{\mathbf{1}}$ & $\boldsymbol{a}_{\mathbf{2}}$ & $\boldsymbol{a}_{\mathbf{3}}$ & $\mathbf{D}_{\mathbf{1}}$ \\
\hline Intima & $1.07 \mathrm{E}-6$ & -7.04 & 4.23 & 2.85 & 24.48 & 25.00 & 23.54 & $8.95 \mathrm{E}-7$ \\
Media & $1.07 \mathrm{E}-6$ & -1.23 & 0.88 & 0.45 & 16.59 & 16.65 & 16.50 & $5.31 \mathrm{E}-6$ \\
Adventitia & $1.07 \mathrm{E}-6$ & -1.28 & 0.85 & 0.44 & 24.63 & 25.00 & 23.74 & $4.67 \mathrm{E}-6$ \\
Artery & $1.07 \mathrm{E}-6$ & -4.73 & 1.70 & 3.09 & -0.39 & 4.41 & -3.25 & $3.63 \mathrm{E}-6$ \\
\hline
\end{tabular}

parameters. In this model, $\mu_{\mathrm{i}}$ and $\alpha_{\mathrm{i}}$ are associated with the shear modulus which can be calculated using the equation, $\mu=\frac{1}{2} \sum_{i=1}^{3} \mu_{i} \alpha_{i}$, and $D_{i}$ represents the compressibility. In this work, the artery and the plaque are assumed to be nearly incompressible. This assumption was realised by specifying a Poisson's ratio of 0.49 for the material and infinitesimal values for $D_{1}\left(D_{2}=D_{3}=0\right)$. Values of model parameters are given in Table 2 for the three layered blood vessel and the homogeneous artery (Prendergast et al., 2003; Zahedmanesh and Lally, 2009). The same Ogden hyperelastic model was also used to describe the constitutive behaviour of the hypocellular and calcified plaques with parameter values given in Table 3 (Loree et al., 1994; Zahedmanesh and Lally, 2009). The stress-strain behaviour, predicted from the Ogden model, was plotted in Figure $3 \mathrm{c}$ for the artery. It can be seen that the intima layer is stiffer than the media and adventitia layers. The homogeneous artery seems to have an averaged behaviour of the three layers. The stress-strain behaviour for the calcified plaque and the hypocellular plaque is compared in Figure 3d, indicating that the calcified plaque is more resistant to stretch or deformation than the hypocellular plaque.

It should be clarified that the strain energy potential given in equation (1) is the third-order Ogden model and not a generic Ogden model. The Ogden model formulation used in this paper is exactly the same as that in Abaqus. Also, the parameter values taken from Zahedmanesh and Lally (2009) were fitted for the same model (i.e. the third-order Ogden model). This is slightly different from the standard (generic) form of Ogden model, which requires particular attention when fitting parameters are taken from published papers that refer to the standard Ogden formulation.

Table 3 Values of the Ogden model parameters for hypocellular and calcified plaques

\begin{tabular}{lllll}
\hline Material & $\boldsymbol{\rho}\left(\mathbf{k g} / \mathbf{m m}^{\mathbf{3}}\right)$ & $\boldsymbol{\mu}_{\mathbf{1}}$ & $\mathbf{a}_{\mathbf{1}}$ & $\mathbf{D}_{\mathbf{1}}$ \\
\hline Hypocellular Plaque & $1.45 \cdot 10^{-6}$ & 0.093 & 8.17 & $4.30 \mathrm{E}-7$ \\
Calcified Plaque & $1.45 \cdot 10^{-6}$ & 0.084 & 20.82 & $2.70 \mathrm{E}-7$ \\
\hline
\end{tabular}

\section{The polynomial model}

To study the effect of different constitutive models, we also considered the incompressible polynomial strain energy potential for both the artery and the hypocellular stenotic plaque based on the work of Gastaldi et al. (2010). The incompressible polynomial strain energy potential is given as:

$$
\begin{aligned}
\mathrm{W}=\mathrm{C}_{10}\left(\mathrm{I}_{1}-3\right) & +\mathrm{C}_{20}\left(\mathrm{I}_{1}-3\right)^{2}+\mathrm{C}_{30}\left(\mathrm{I}_{1}-3\right)^{3} \\
& +\mathrm{C}_{40}\left(\mathrm{I}_{1}-3\right)^{4}+\mathrm{C}_{50}\left(\mathrm{I}_{1}-3\right)^{5}+\mathrm{C}_{60}\left(\mathrm{I}_{1}-3\right)^{6}
\end{aligned}
$$

where $\mathrm{C}_{\mathrm{i} 0}(\mathrm{i}=1-6)$ are model parameters. Unlike the Ogden model in Eq. (2), the second invariant of the stretch tensor is not accounted for in Eq. (3). The artery was modelled as a 3-layered structure and the corresponding values for all parameters are given in Table 4 (Gastaldi et al., 2010). Model parameter values for hypocellular plaque are also given in Table 4 (Loree et al., 1994). Figure 3e shows the stress-strain behaviour, predicted from the incompressible polynomial strain energy potential, for the artery and the hypocellular plaque, which is similar to those predicted from Ogden model (Figure $3 \mathrm{c}$ and $\mathrm{d}$ ).

\section{The Holzapfel-Gasser-Ogden model}

Experimental tests on human arteries highlighted the anisotropic behaviour of such biological tissues (Holzapfel et al., 2000; Holzapfel et al., 2005). The effects of using an anisotropic hyperelastic strain energy potential for the modelling of arterial layers is also considered in this study. For this purpose, a Holzapfel-Gasser-Ogden (HGO) model (Holzapfel et al., 2000; Gasser et al., 2006) has been used, with a strain energy potential given as (ABAQUS, 2014)

$$
\begin{aligned}
W & =C_{10}\left(I_{1}-3\right)+\frac{k_{1}}{2 k_{2}}\left[\exp \left(k_{2}\langle E\rangle^{2}\right)-1\right]+\frac{1}{D}\left(\frac{(J)^{2}-1}{2}-\ln J\right), \\
E & =\kappa\left(I_{1}-3\right)+(1-3 \kappa)\left[I_{4}-1\right]
\end{aligned}
$$

where $C_{10}, D, k_{1}, k_{2}$ and $\kappa$ are material parameters, and $I_{4}$ is the invariant of Cauchy-Green deformation tensor and the mean direction vector of fibre family. The strain-like quantity $E$ characterizes the deformation of the fibre family and the operator \langle\rangle stands for the Macauley bracket. The parameters of the model were calibrated to fit the experimental data given in Holzapfel et al. (2005), which are the same set of data used to fit the parameters for the Ogden and the polynomial models in Sections Finite element model and The polynomial model. Fitted model parameters are given in Table 5 for all three vessel layers, which give the stressstretch responses that are in good agreement with the experimental data in both circumferential and longitudinal directions (Figure 4). 
Table 4 Values of the polynomial model parameters for the three vessel wall layers and the hypocellular plaque

\begin{tabular}{llllllll}
\hline Material & $\mathbf{\rho}\left(\mathbf{k g} / \mathbf{m m}^{\mathbf{3}}\right)$ & $\mathbf{C}_{\mathbf{1 0}}$ & $\mathbf{C}_{\mathbf{2 0}}$ & $\mathbf{C}_{\mathbf{3 0}}$ & $\mathbf{C}_{\mathbf{4 0}}$ & $\mathbf{C}_{\mathbf{5 0}}$ & $\mathbf{C}_{\mathbf{6 0}}$ \\
\hline Intima & $1.07 \mathrm{E}-6$ & $6.79 \mathrm{E}-3$ & 0.54 & -1.11 & 10.65 & -7.27 & 1.63 \\
Media & $1.07 \mathrm{E}-6$ & $6.52 \mathrm{E}-3$ & $4.89 \mathrm{E}-2$ & $9.26 \mathrm{E}-3$ & 0.76 & -0.43 & 0.087 \\
Adventitia & $1.07 \mathrm{E}-6$ & $8.27 \mathrm{E}-3$ & $1.20 \mathrm{E}-2$ & 0.52 & -5.63 & 21.44 \\
Hypocellular Plaque & $1.45 \mathrm{E}-6$ & $2.38 \mathrm{E}-3$ & 0.19 & 0.39 & 3.73 & -2.54 & 0.57 \\
\hline
\end{tabular}

\section{Results and discussion}

\section{Effect of balloon folding}

The comparison of the diameter change against the pressure is showed in Figure 5 for simulations using rubber balloon and folded balloon. Here, Ogden model has been used to describe the constitutive behaviour of both artery (3 layers) and plaque (hypocellular). The simulations using 3-folded balloon show a sustained expansion of the system at a pressure of $0.38 \mathrm{MPa}$. The sustained expansion continued at a constant rate $(18.5 \mathrm{~mm} / \mathrm{MPa})$ until a pressure of $0.51 \mathrm{MPa}$ is reached. Afterwards, the expansion reached a point of saturation where the system expanded at an extremely low rate to a diameter of $4.70 \mathrm{~mm}$ at the peak pressure of $1.4 \mathrm{MPa}$. Simulated diameter change using the polyurethane runner balloon behaved very differently from that using the folded balloons. For rubber balloon, the sustained period of expansion started at a higher pressure $(0.80 \mathrm{MPa})$ compared to that for a folded balloon, and also the expansion rate is lower than that for a folded balloon. At a pressure of $1.1 \mathrm{MPa}$, the expansion reached a saturation stage. However, the final diameters achieved at the peak pressure are similar $(\sim 4.70 \mathrm{~mm})$ for both rubber and folded balloons. During deflation, the system recoiled nonlinearly until the balloons were completely separated from the stent and the artery. The diameter achieved at the end of deflation was higher for folded balloons than that for rubber balloon. Specifically, the final diameter of the stented artery is $4.04 \mathrm{~mm}$ for the folded balloon and $3.73 \mathrm{~mm}$ for the rubber balloon.

The system expanded using a rubber balloon showed higher recoiling effect (22\%) compared to that using a folded balloon (12\%). These results can be explained by the different volume of plastic deformation achieved in the expanded stent, which was calculated to be $29 \%$ for the case of rubber balloon and 58\% for the case of folded balloons. The volume of plastic deformation is closely linked with the recoiling of the system. The stent with

Table 5 Values of the Holzapfel-Gasser-Ogden model parameters for the three vessel layers

\begin{tabular}{lllllll}
\hline Material & $\boldsymbol{\rho}\left(\mathbf{k g} / \mathbf{m m}^{\mathbf{3}}\right)$ & $\mathbf{C}_{\mathbf{1 0}}$ & $\mathbf{k}_{\mathbf{1}}$ & $\mathbf{k}_{\mathbf{2}}$ & $\mathbf{K}$ & $\mathbf{D}$ \\
\hline Intima & $1.07 \mathrm{E}-6$ & $2.3 \mathrm{E}-2$ & 25 & 1200 & 0.308 & $8.95 \mathrm{E}-7$ \\
Media & $1.07 \mathrm{E}-6$ & $1.4 \mathrm{E}-3$ & 0.18 & 100 & 0.314 & $5.31 \mathrm{E}-6$ \\
Adventitia & $1.07 \mathrm{E}-6$ & $8.32 \mathrm{E}-3$ & 4 & 1000 & 0.312 & $4.67 \mathrm{E}-6$ \\
\hline
\end{tabular}

larger volume of plastic deformation provides stronger resistance to the elastic recovery of the deformed artery, which explains the less recoiling effect for systems expanded using the folded balloons. However, the dogboning effect was lower for system expanded using rubber balloon (18\%) than that using folded balloon (21\%), which might be due to the lack of radial constraints for the folded balloons in our simulation.

The von Mises stress distributions for the stent and the artery are shown in Figure $6 \mathrm{a}$ and b, respectively. On the stent, the maximum stress was significantly higher if the expansion was simulated using folded balloons, i.e. $1390 \mathrm{MPa}$ for the 3-folded balloon. These values are even higher than the ultimate tensile strength of the material, which is around $1012 \mathrm{MPa}$ (see Figure 3a). This indicates a risk of failure during the stent expansion. On contrary, the simulation using rubber balloon gave a much lower maximum stress, i.e. $778 \mathrm{MPa}$, which is below the UTS of the material. On the plaque, the stress was also considerably higher for simulations using folded balloons. The maximum value was found to be $1.16 \mathrm{MPa}$ for the 3-folded balloon at the end of deployment. For a rubber balloon, the stress on the plaque has a maximum value of only $0.58 \mathrm{MPa}$, about half of those for folded balloon. These results are consistent with the different levels of expansion achieved by the artery-plaque system when using rubber and folded balloons.

The results suggest that balloon type has a significant effect on stent-artery expansion and their stress distributions. Stent deployment using folded balloon led to a sustained expansion until the balloon is unfolded. After this, a saturation stage is reached and further expansion became very slow and difficult. Furthermore, the recoiling appeared to be lower for a folded balloon than that for a rubber balloon, resulting in an overall larger expansion of the artery for folded balloon. This behaviour was mainly due to the fact that the balloon remained partially in contact with the stent during the whole deflation process, preventing the artery from recoiling completely. The dogboning was also affected by the balloon folding, but this may be due to different boundary conditions used for the folded balloon and rubber balloon. The ends of folded balloon are free of constraints in radial direction, and consequently less prohibitive for the recoiling at the distal sections, resulting in the increased dogboning effect. 


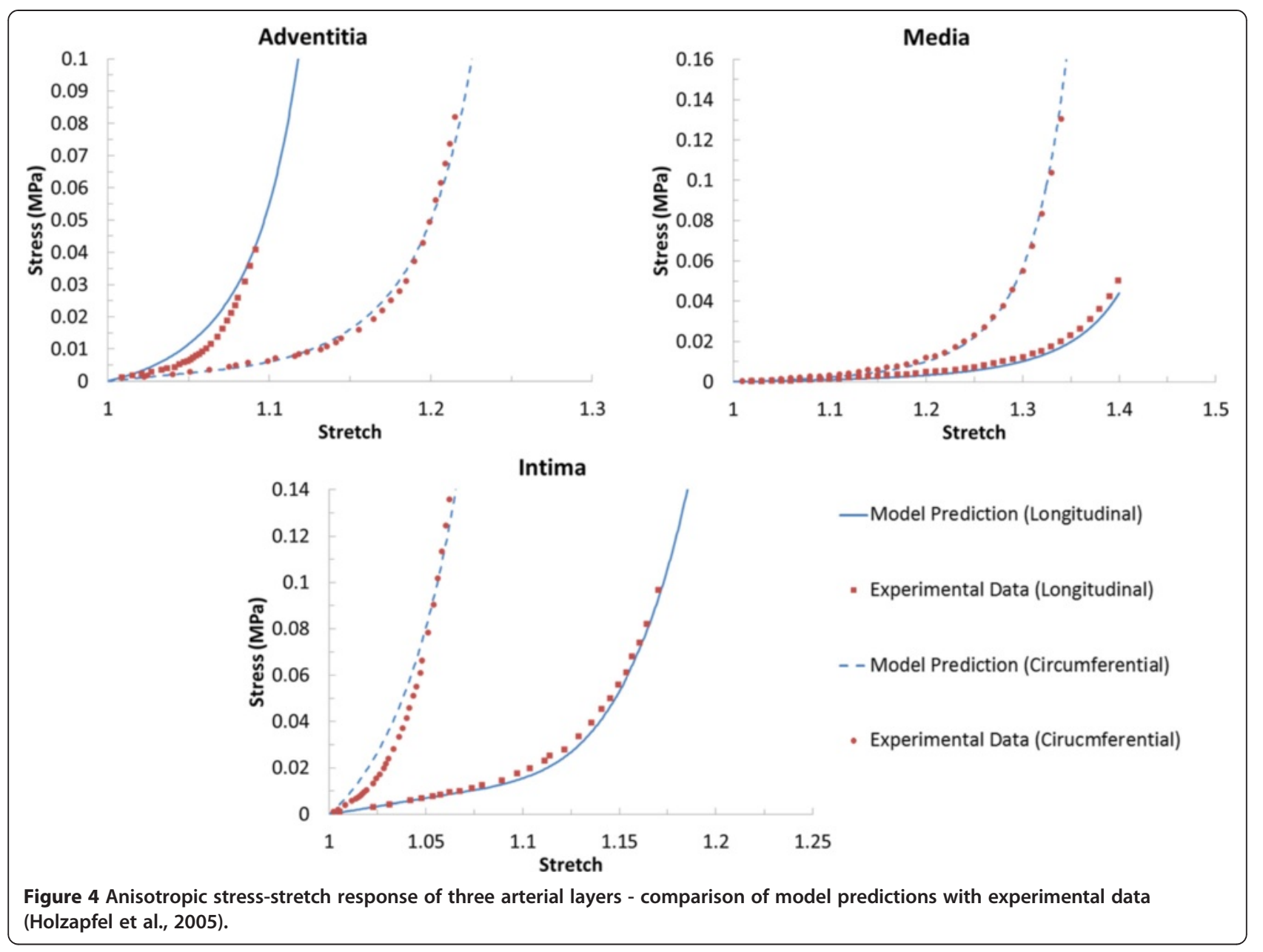

It should be noted that there is a limitation for the simulations using the folded balloon. The folded balloon model adopted in this paper lacks the interaction with the catheter, which led to an overestimation of the dogboning effect during the expansion as also reported in Martin and Boyle (2013). However, this difference was

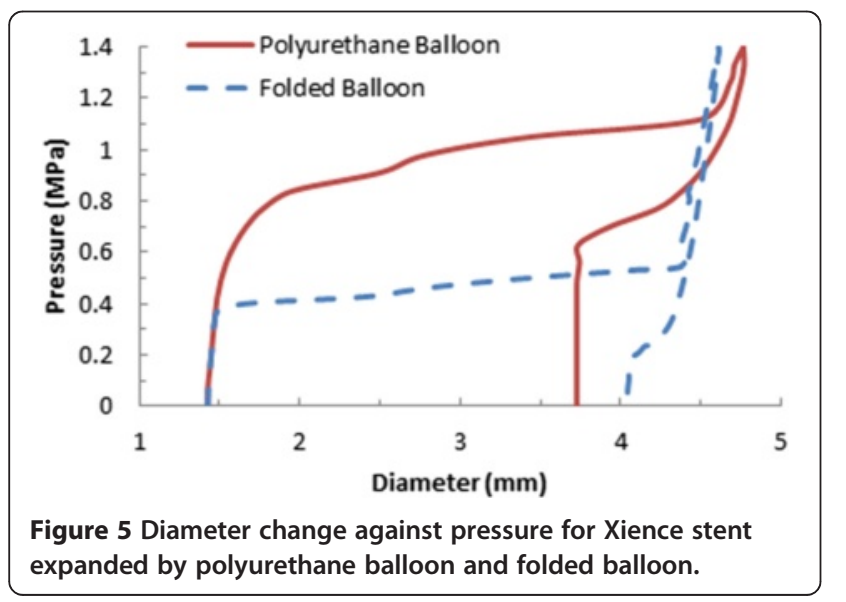

noticed only at the beginning of the expansion, and became negligible (around 2\%) at the final stage of expansion. For this reason, it is believed that the key results will not be affected by neglecting the interaction between folded balloon and angioplasty catheter.

\section{Effect of artery constraints}

The effect of artery constraints on the stent expansion is shown in Figure 7, where Ogden model has been used to describe the constitutive behaviour of both artery (3 layers) and plaque (hypocellular). Three types of constraints were simulated, i.e., free of constraint artery, partially constrained artery and fully constrained artery. The free artery and fully constrained artery are two limit cases which also serve as a lower bound and an upper bound. For a free artery, its ends are able to move both radially and axially. For a fully constrained artery, its ends are fixed in all directions. Partially constrained artery was modelled using spring elements with a stiffness of $1 \mathrm{kN} / \mathrm{m}$. The spring elements connect the ends of the artery to a fixed point. As shown in Figure 7, the diameter at the maximum pressure was the same for all three 
(a)

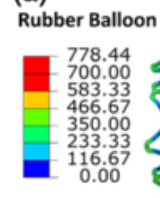

Folded Balloon

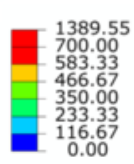

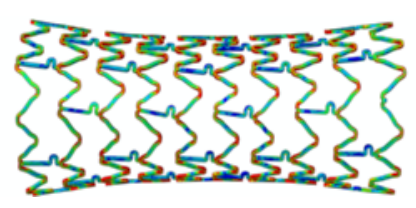

(b)
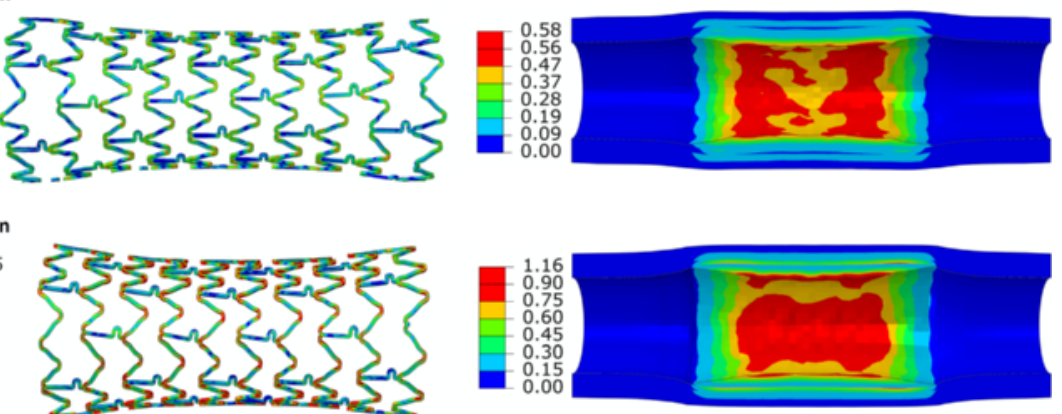

Figure 6 Contour plot of von Mises stress in (a) the stent and (b) the artery-plaque system for simulations using rubber balloon and 3-folded balloon.

different boundary conditions, with a value of $4.70 \mathrm{~mm}$. However, the finally achieved expansion was the highest if the artery was free to move. The stent-artery stabilised at a diameter of $4.12 \mathrm{~mm}, 4.03 \mathrm{~mm}$ and $3.73 \mathrm{~mm}$ for free, partially and fully constrained artery, respectively. This was mainly due to the different radial compression imposed by the different types of artery constraints. In addition, a lower recoiling effect was observed for free artery (13\%) than those for partially (15\%) and fully constrained artery (22\%). The fully constrained artery also gave higher dogboning effect (18\%) than the fully free artery $(6.1 \%)$ and partially constrained artery $(8.7 \%)$.

Figure 8 shows the von Mises stress distributions on the stenotic artery with free, partially and fully constrained artery ends. The stress contours on the artery were similar in all cases, with the maximum stresses mostly located on the plaque. The fully constrained artery exhibited less stress magnitudes $(0.58 \mathrm{MPa})$ than the free one $(1.05 \mathrm{MPa})$ and the partially constrained one (1.01 MPa), reflecting the reduced level of stretch and deformation of the artery if fully constrained.

\section{Effect of artery constitutive models}

Second stretch invariant in strain energy potential (Ogden model vs. Polynomial model)

Ogden model and polynomial model use different strain energy potential to describe hyperelastic material behaviour. Figure 9a shows the diameter change against the pressure during the expansion of the system simulated using Ogden model and polynomial model, where the 3layered structure has been considered for the artery with hypocellular plaque. For the polynomial model, the system expansion reached the point of saturation at a larger diameter $(5.11 \mathrm{~mm})$ due to the absence of the second stretch invariant in the strain energy function. And a maximum expansion of $5.20 \mathrm{~mm}$ is obtained at the peak pressure of $1.2 \mathrm{MPa}$, compared to $4.70 \mathrm{~mm}$ for Ogden model. However, for both models, the system exhibited

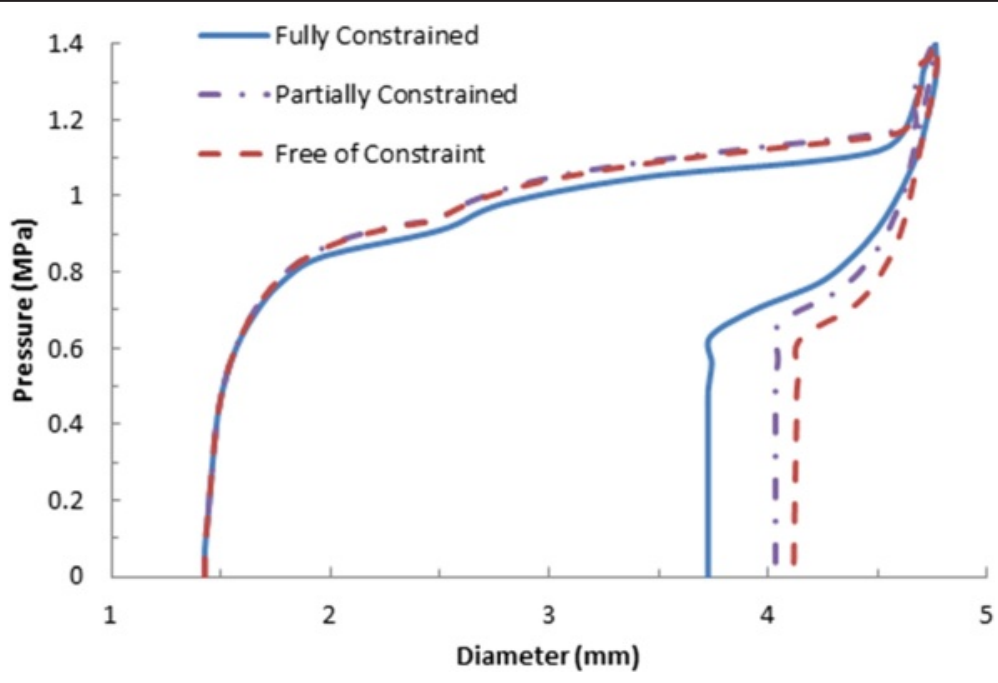

Figure 7 Diameter change against pressure for three different types of artery constraints. 


\section{Fully Constrained}

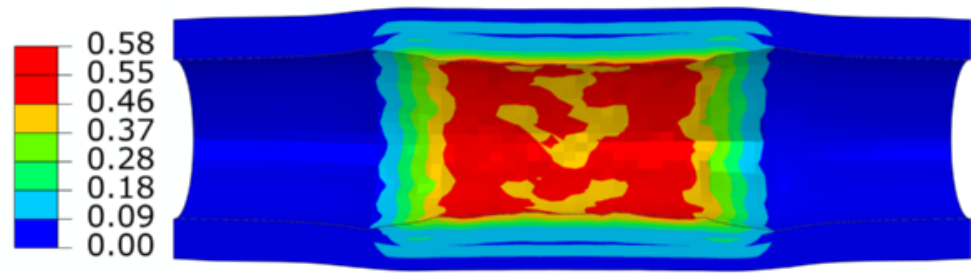

Partially Constrained

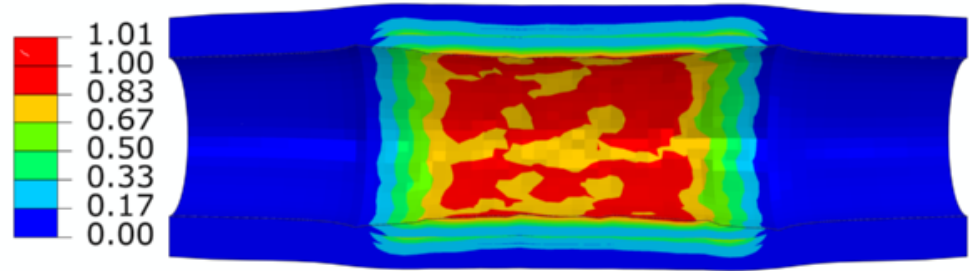

Free of Constraint

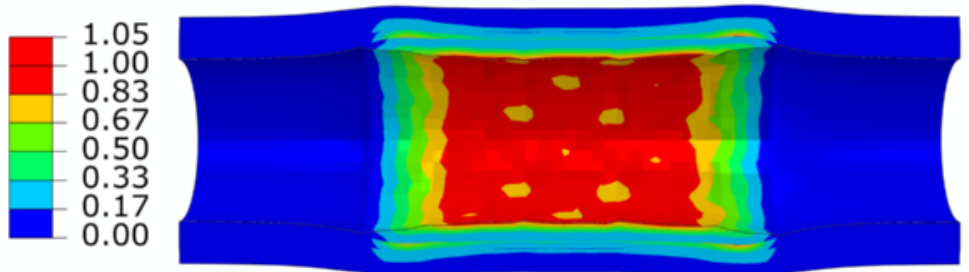

Figure 8 Contour plot of von Mises stress on the artery-plaque system for three different types of artery constraints.

similar recoiling effects (22\% for Ogden model and 20\% for polynomial model). Consequently, the system achieved a diameter of $4.11 \mathrm{~mm}$ for polynomial model after deflation, which is larger than that for Ogden model $(3.73 \mathrm{~mm})$. The stress distribution on the artery for the two models is shown in Figure 9b, and the stress level was higher for polynomial model $(0.79 \mathrm{MPa})$ due to more severe deformation. The importance of the second stretch invariant $\left(\mathrm{I}_{2}\right)$ has been discussed in Horgan and Smayda (2012) and Khajehsaeid et al. (2013). It was reported that the strain-energy potential with the absence of $\mathrm{I}_{2}$ is unable to capture some significant physical effects such as simple shear, strain stiffening at large stretches and torsion of a circular cylinder. Our work also confirmed the influence of $\mathrm{I}_{2}$ in modelling stent deployment. Without considering $\mathrm{I}_{2}$, the obtained expansion seems overestimated and could generate some misleading results.

Artery wall model (3-layer artery vs. Homogeneous artery) The blood vessel can be simulated as either 3-layer structure or homogeneous material. Using the Ogden strain energy potential, stent deployment has been modelled for both cases (with hypocellular plaque). As shown in Figure 10a, the expansion of the system is very similar for both models. The system reached a diameter of $4.70 \mathrm{~mm}$ and $4.80 \mathrm{~mm}$ for 3-layer model and homogeneous model, respectively, at the peak pressure of $1.4 \mathrm{MPa}$, and then recoiled to a final diameter of $3.73 \mathrm{~mm}$ and $3.63 \mathrm{~mm}$, respectively, after balloon deflation. This suggests that using a homogeneous model or a 3-layer model for the artery wall does not influence the expansion behaviour. The stress distribution on the artery is shown in Figure 10b, which shows similar maximum stress magnitudes for both cases $(0.57 \mathrm{MPa}$ and $0.58 \mathrm{MPa}$, respectively). For layered model, the high stresses were found at the most parts of the stenotic plaque, while for homogeneous model, stress concentrations occurred at the ends of the plaque. Also, considering the layered structure of vessel wall generated the discontinuous stress distribution across the wall thickness, especially in the intima layer, a result of material heterogeneity across the vessel wall. This phenomenon can also be observed from the results obtained earlier (e.g. Figures 6b, 8 and 9b). We have particularly checked the stress and strain variations across the three layers. All strain components are continuous across the interfaces due to the compatibility requirement in deformation. However, all stresses are discontinuous across the interfaces due to different material properties of the three layers. These results are reasonable in our point of view. As the strain is continuous, the stress ought to be discontinuous due to the property mismatch across the interface. 


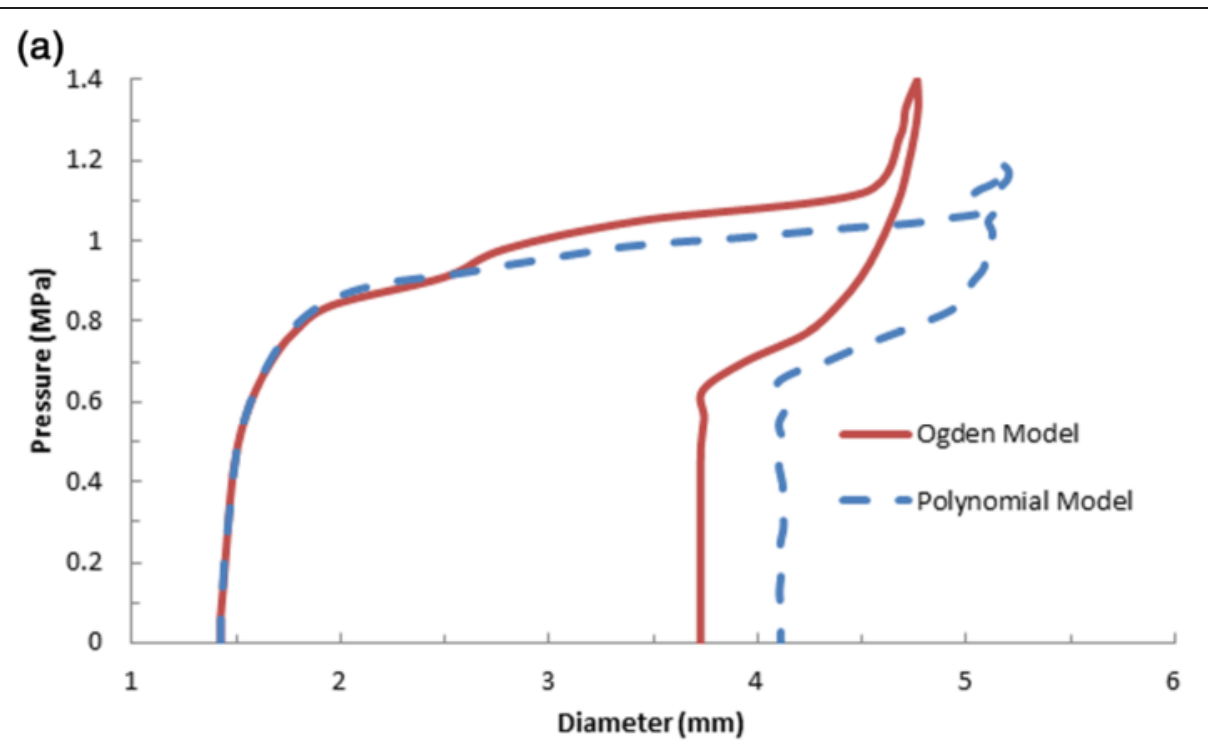

(b)

Ogden Model

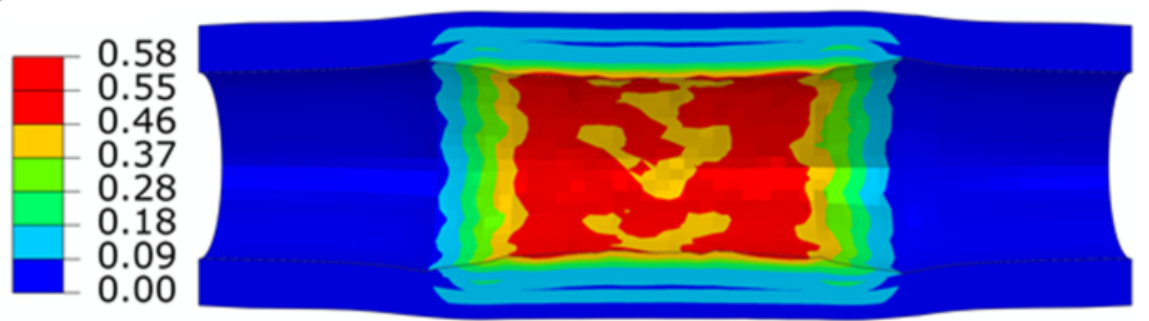

\section{Polynomial Model}

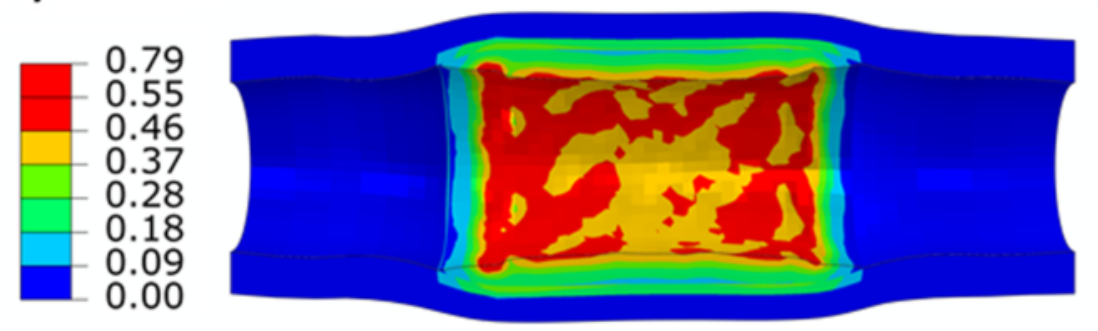

Figure 9 Comparison of (a) diameter change for the stent and (b) von Mises stress distribution in the artery-plaque system for Ogden and polynomial constitutive models.

\section{Anisotropic behaviour of arterial layers}

Simulation of stent deployment was also carried out using an anisotropic model for the three arterial layers (see Table 5 and Figure 4). The hypocellular plaque was considered and described by the isotropic Ogden model. The results of stent expansion and stress distribution in artery- plaque system are shown in Figure 11, in a comparison with those obtained from isotropic arterial model. At the peak pressure $(1.4 \mathrm{MPa})$, the maximum diameter achieved using the anisotropic model was only $4.10 \mathrm{~mm}$, which is much reduced when compared to that, i.e.
$4.70 \mathrm{~mm}$, achieved using the isotropic model for the layers. After recoiling, the diameter was settled at $3.80 \mathrm{~mm}$ for the anisotropic model, which is larger than that $(3.73 \mathrm{~mm})$ computed from the isotropic model. This is due to the significant reduction in recoiling, only $8 \%$, for the anisotropic model (22\% for isotropic model). The stress distribution on the artery-plaque system is compared in Figure 11b, and the anisotropic model generated slightly higher levels of stress than the isotropic model, with a maximum value of $0.70 \mathrm{MPa}(0.65 \mathrm{MPa}$ for isotropic model). High stress levels were mainly obtained in the intima and adventitia 


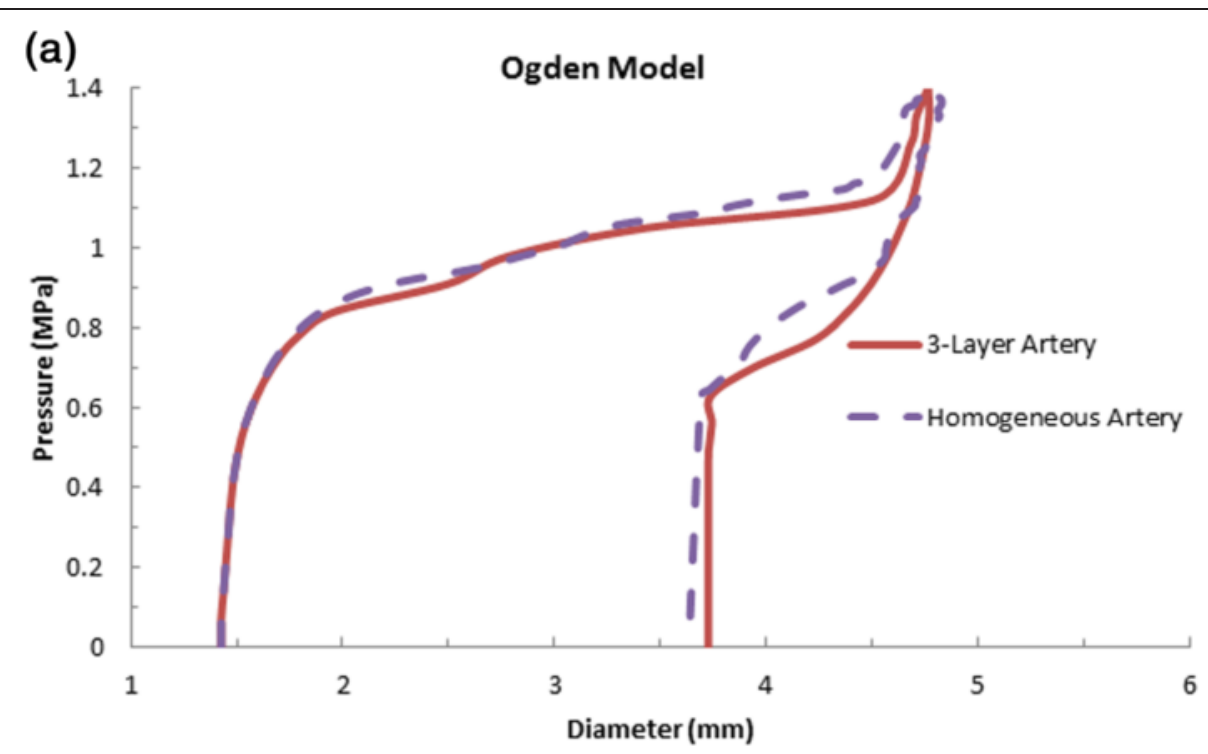

(b)

\section{3-Layer Artery}

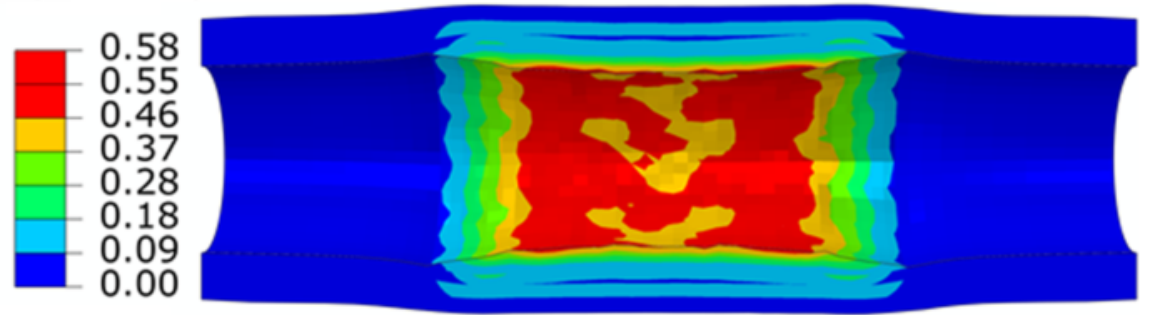

Homogeneous Artery

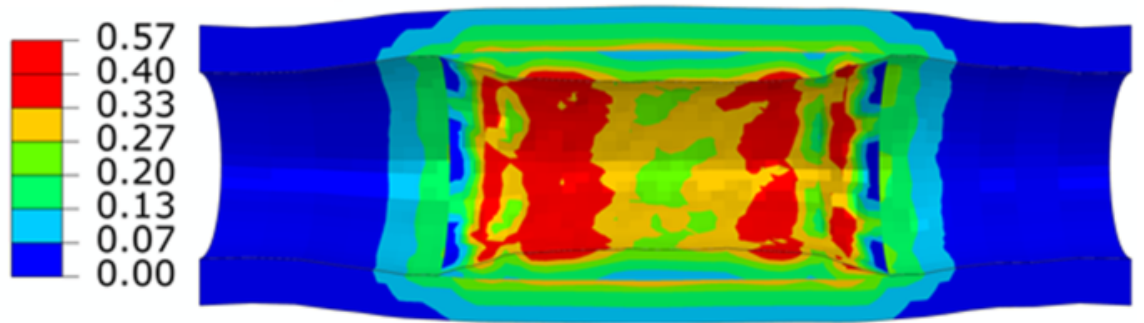

Figure 10 Comparison of (a) diameter change for the stent and (b) von Mises stress distribution in the artery-plaque system for 3-layer and homogeneous artery models.

layer as well as on the stenotic plaque surface. The media has the lowest stress level due to its soft stress-strain response in the circumferential direction.

\section{Stenosis composition (Hypocellular plaque vs. Calcified plaque)} The stenotic plaque can be modelled as either hypercellular plaque or calcified plaque depending on its composition. Simulations have been carried out for both plaque compositions using the Ogden strain energy potential where the 3-layer structure was considered for the artery. As shown in Figure 12a, the expansion of the system is very limited for calcified plaque, reaching a maximum expansion of only $3.49 \mathrm{~mm}$ at peak pressure and recoiling to a diameter of $3.12 \mathrm{~mm}$ after balloon deflation. The reason is that the calcified plaque was much stiffer than the hypocellular plaque, which prohibited the effective expansion of the artery system. Consequently, the dogboning was also significantly higher for calcified plaque (39\%) than the hypocellular plaque model (18\%), due to the under-expansion of the system. The maximum stress on the artery for calcified plaque was also very high $(0.90 \mathrm{MPa})$, and severe stress 


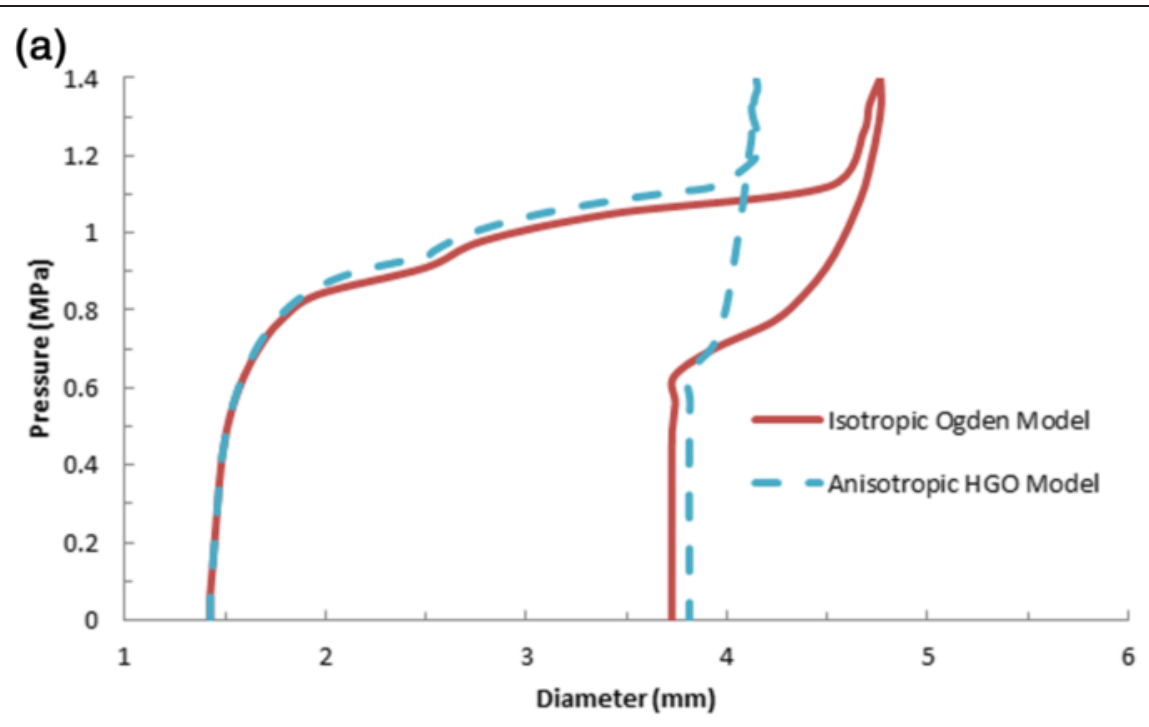

(b)

Isotropic Artery

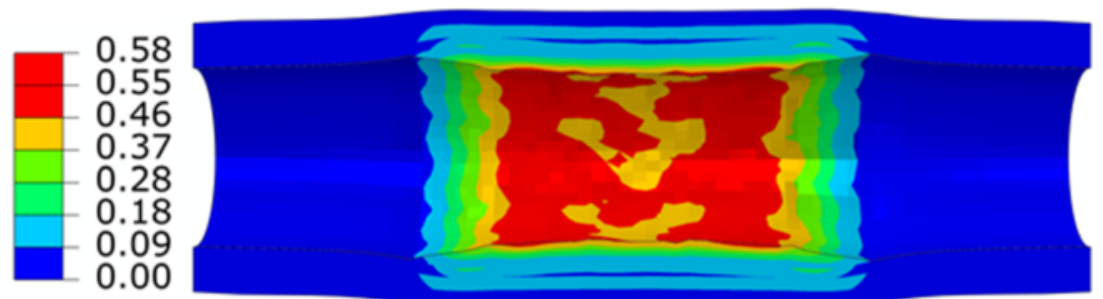

Anisotropic Artery

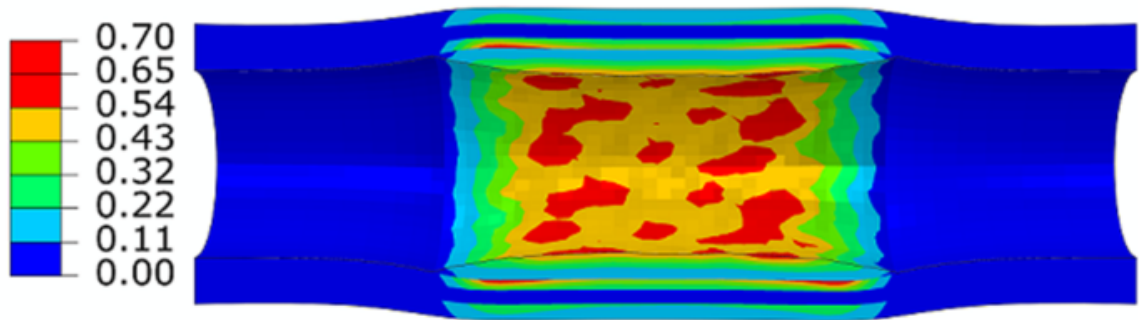

Figure 11 Comparison of (a) diameter change for the stent and (b) von Mises stress distribution in the artery-plaque system for isotropic and anisotropic artery models.

concentration is observed at the ends of plaque where the stent and the plaque are in strong contact caused by the strong dogboning effect (Figure 12b).

From these results, it is plausible to say that the diameter change of the artery during deployment is highly determined by the composition of the stenotic plaque. The stent deployment simulated using calcified plaque model reached a saturation of expansion far earlier than that using hypocellular plaque model. The finally achieved expansion for calcified plaque model is also significantly lower than that for hypocellular plaque models. However, the recoiling effect was consistent with each other, regardless of the artery and plaque constitutive models.

\section{Conclusions}

The choice of balloon type, system constraints and artery constitutive models has a great influence on the simulation of stent expansion inside a stenotic artery. Simulations using folded and rubber balloons generate significantly different results in the stent expansion, such as sustained stent expansion behaviour, stress levels on the system and finally achieved diameter. The type of boundary conditions used for the artery highly affects the recoiling of the system, showing that over-constraints lead to higher recoiling effect but a decrease of stress magnitude on the artery wall due to reduced stretch. The use of different artery-plaque constitutive models also affects 


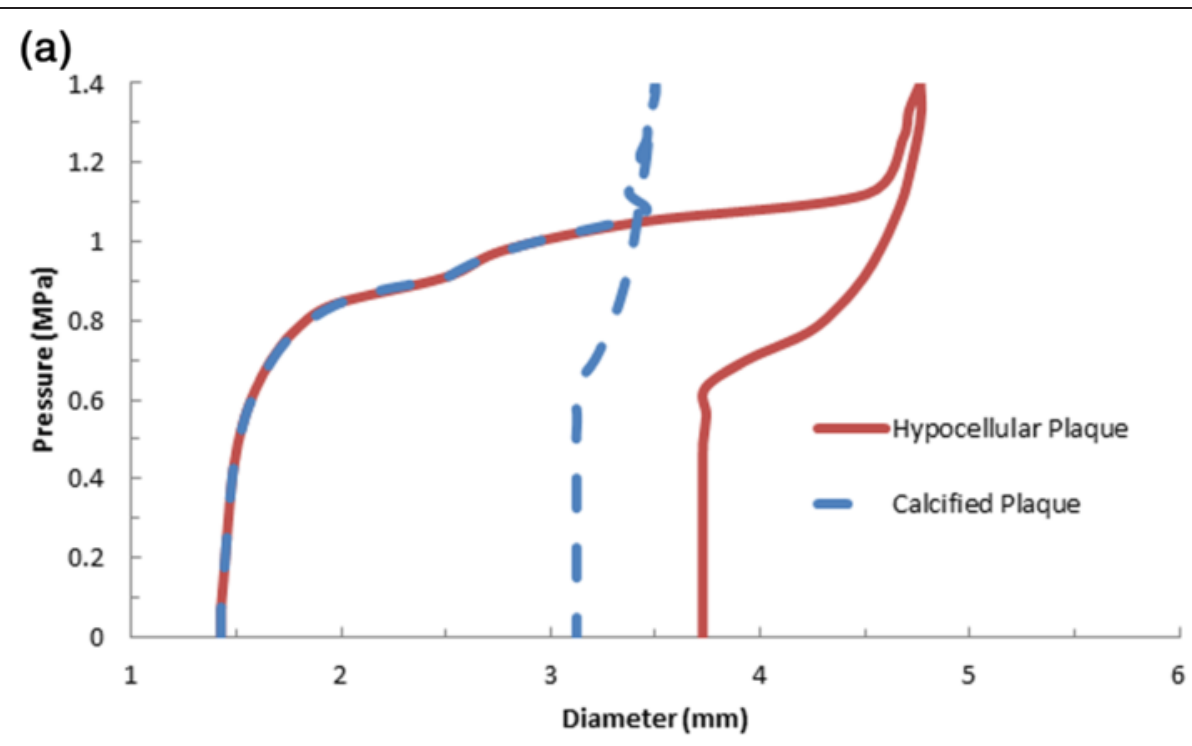

(b)

\section{Hypocellular Plaque}

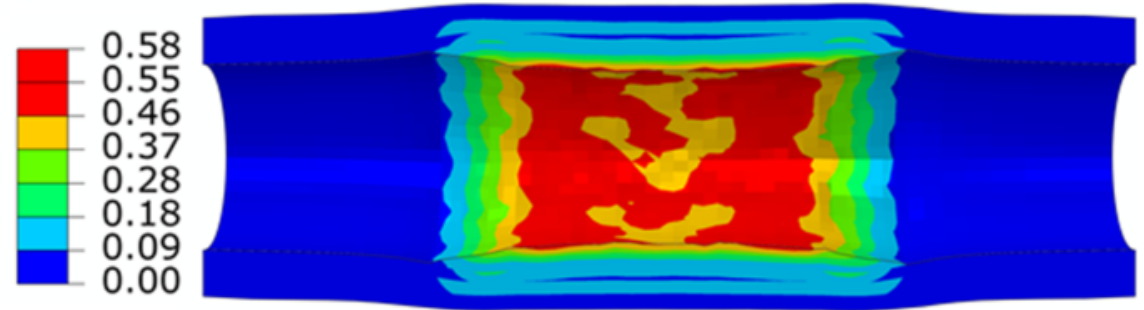

\section{Calcified Plaque}

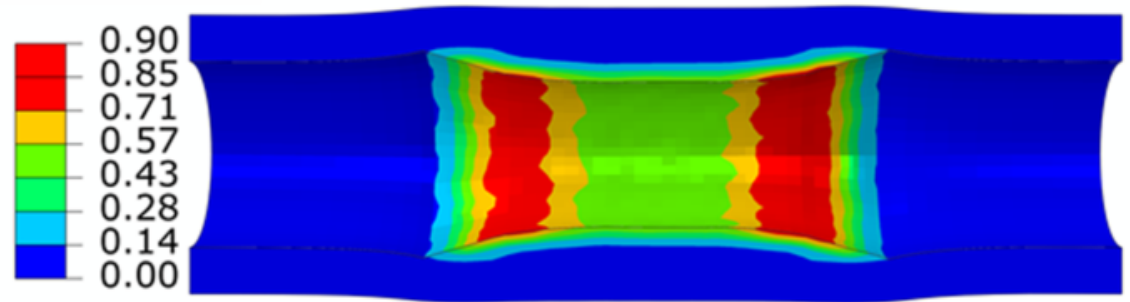

Figure 12 Comparison of (a) diameter change for the stent and (b) von Mises stress distribution in the artery-plaque system for hypocellular and calcified plaque models.

the simulated expansion behaviour of the system. For instance, calcified plaque model leads to a considerably lower expansion than hypocellular plaque model, with also higher stress levels. Stent expansion exhibits a saturation stage for simulation using Ogden model, which has not been observed for 6-parameter polynomial models due to the negligence of the second stretch invariant in the strain energy potential. Consideration of 3-layer structure of the artery wall showed the discontinuous stress distributions across the thickness of the blood vessel which cannot be captured by the homogeneous artery constitutive model. The anisotropy of the vessel layers leads to a lower maximum expansion and a higher stress level in the inner and outer arterial layers and on the surface of the stenotic plaque. These important factors need to be considered carefully in order to produce reliable and conclusive results in stent deployment simulations.

In conclusion, the hyperelastic strain energy potential that includes the first two invariants of the stretch tensor should be adopted to describe the constitutive behaviour of both the artery and the stenotic plaque. The constitutive model should also take into account the layered structure of the artery and the anisotropy of each layer. Over constraint of the artery ends can lead 
to an overestimation of recoiling effect of the system. From the results of this paper, it is more realistic to partially constrain the artery using spring elements with a proper stiffness constant. The plaque composition is also a major factor that affects the process of stent deployment and should be considered in computational modelling. For balloon-expandable stents, folded balloon should be modelled in order to obtain a more realistic diameter-pressure response of the system.

\section{Competing interests}

The authors declare that there are no competing interests.

\section{Authors' contribution}

AS planned and carried out this study and drafted the manuscript. LGZ supervised the research, contributed to the interpretation of results and writing of the manuscript. All the authors read and approved the manuscript.

Received: 17 September 2014 Accepted: 18 December 2014 Published online: 05 May 2015

\section{References}

ABAQUS (2014) Version 6.13, User manual, Dassault Systèmes, Vélizy-Villacoublay, France.

Bower AF (2008) Advanced element formulations Incompatible modes; reduced integration; and hybrid elements. In: Applied Mechanics of Solids. http:// solidmechanics.org/text/Chapter8_6/Chapter8_6.htm. Accessed 09 Dec 2014

Chua SND, McDonald BJ, Hashimi MSJ (2003) Finite element simulation of stent and balloon interaction. J Mater Process Tech 143-144:591-597

De Beule M, Mortier P, Carlier SG, Verhegghe B, Impe RV, Verdonck P (2008) Realistic finite element-based stent design: The impact of balloon folding. J Biomech 41:383-389

Dixon SA, Heikes RG, Vito RP (2003) Constitutive modeling of porcine coronary arteries using designed experiments. ASME J Biomech Eng 125:274-279

Gasser TC, Ogden RW, Holzapfel GA (2006) Hyperelastic modelling of arterial layers with distributed collagen fibre orientations. J R Soc Interface 6:15-35

Gastaldi D, Morlacchi S, Nichetti R, Capelli C, Dubini G, Petrini L, Migliavacca F (2010) Modelling of the provisional side-branch stenting approach for the treatment of atherosclerotic coronary bifurcations: effects of stent positioning. Biomech Model Mechan 9:551-561

Gervaso F, Capelli C, Petrini L, Lattanzio S, Di Virgilio L, Migliavacca F (2008) On the effects of different strategies in modelling balloon-expandable stenting by means of finite element method. J Biomech 41:1206-1212

Gijsen FJH, Migliavacca F, Schievano S, Socci L, Petrini L, Thury A, Wentzel JJ, van der Steen AFW, Serruys PWS, Dubini G (2008) Simulation of stent deployment in a realistic human coronary artery. Biomed Eng Online 7:23

Holzapfel GA, Gasser TC, Ogden RW (2000) A new constitutive framework for arterial wall mechanics and a comparative study of material models. J Elasticity Phys Sci Solids 61:1-48

Holzapfel GA, Gasser TC, Ogden RW (2004) Comparison of a structural model with a Fung-type model using a carotid artery: issues of material stability. J Biomech Eng 126:264-275

Holzapfel GA, Ogden RW (2010) Constitutive modeling of arteries. Proc R Soc Ser A 466:1551-1597

Holzapfel GA, Sommer G, Gasser CT, Regitnig P (2005) Determination of layer-specific mechanical properties of human coronary arteries with nonatherosclerotic intimal thickening and related constitutive modelling. Am J Phisiol Heart C 289: $\mathrm{H} 2048-\mathrm{H} 2058$

Horgan CO, Smayda MG (2012) The importance of the second strain invariant in the constitutive modeling of elastomers and soft biomaterials. Mech Mater 51:43-52

Ju F, Xia Z, Sasaki K (2008) On the finite element modelling of balloonexpandable stents. J Mech Behav Biomed Mater 1:86-95

Khajehsaeid H, Arghavani J, Naghdabadi R (2013) A hyperelastic constitutive model for rubber-like materials. Eur J Mech A Solid 38:144-151

Lally C, Dolan F, Prendergast PJ (2005) Cardiovascular stent design and vessel stresses: a finite element analysis. J Biomech 38:1574-1581
Loree HM, Grodzinsky AJ, Park SY, Gibson L, Lee RT (1994) Static circumferential tangential modulus of human atherosclerotic tissue. J Biomech 27:195-204

Martin D, Boyle F (2013) Finite element analysis of balloon-expandable coronary stent deployment: Influence of angioplasty balloon configuration. Int J Numer Meth Biomed Eng 29:1161-1175

Medtronic Technical Bulletin (2003) Advantages of cobalt alloy for coronary stents. http://wwwp.medtronic.com/newsroom/content/1110132739468.pdf.

Morlacchi L, Colleoni SG, Cárdenes R, Chiastra C, Diez JL, Larrabide I, Migliavacca F (2013) Patient-specific simulations of stenting procedures in coronary bifurcations: Two clinical cases. Med Eng Phys 35:1272-1281

Mortier P, De Beule M, Van Loo D, Verhegghe B, Verdonck P (2009) Finite element analysis of side branch access during bifurcation stenting. Med Eng Phys 31:434-440

Nolan DR, Gowe AL, Destrade RW, Ogden RW, McGarry JP (2014) A robust anisotropic hyperelastic formulation for the modelling of soft tissue. J Mech Behav Biomed Mater 39:48-60

Pericevic I, Lally C, Toner D, Kelly DJ (2009) The influence of plaque composition on underlying arterial wall stress during stent expansion: The case for lesion-specific stents. Med Eng Phys 31:428-433

Prendergast PJ, Lally C, Daly S, Reid AJ, Lee TC, Quinn D, Dolan F (2003) Analysis of prolapse in cardiovascular stents: a constitutive equation for vascular tissue and finite-element modelling. ASME J Biomech Eng 125:692-699

Schiavone A, Zhao LG, Abdel-Wahab AA (2014) Effects of material, coating, design and plaque composition on stent deployment inside a stenotic artery - finite element simulation. Mat Sci Eng C 42:479-488

Simulia (2010) Best Practices for Stent Analysis with Abaqus. Simulia Learning, Answer 4516

Zahedmanesh H, Kelly DJ, Lally C (2010) Simulation of a balloon expandable stent in a realistic coronary artery - Determination of the optimum modelling strategy. J Biomech 43:2126-2132

Zahedmanesh H, Lally C (2009) Determination of the influence of stent strut thickness using the finite element method: implications for vascular injury and in-stent restenosis. Med Biol Eng Comput 47:385-393

Zhang Y, Dunn ML, Hunter KS, Lanning C, Ivy DD, Claussen L, Chen SJ, Shandas R (2007) Application of a microstructural constitutive model of the pulmonary artery to patient-specific studies: validation and effect of orthotropy. ASME J Biomech Eng 129:193-201

Zhao S, Gu L, Froemming SR (2012a) On the importance of modeling stent procedure for predicting arterial mechanics. ASME J Biomech Eng 134:121005-1

Zhao S, Gu L, Froemming SR (2012b) Finite element analysis of the implantation of a self-expanding stent: impact of lesion calcification. ASME J Med Device 6:021001

\section{Submit your manuscript to a SpringerOpen ${ }^{\odot}$ journal and benefit from:}

- Convenient online submission

- Rigorous peer review

- Immediate publication on acceptance

- Open access: articles freely available online

- High visibility within the field

- Retaining the copyright to your article

Submit your next manuscript at $>$ springeropen.com 